\title{
Characterizing potential wildland fire fuel in live vegetation in the Mediterranean region
}

\author{
Silvano Fares ${ }^{1}$ (D) - Sofia Bajocco ${ }^{2}$ - Luca Salvati ${ }^{1}$ - Nicolò Camarretta ${ }^{3}$. \\ Jean-Luc Dupuy ${ }^{4}$ - Gavriil Xanthopoulos ${ }^{5}$ - Mercedes Guijarro ${ }^{6}$ • Javier Madrigal ${ }^{6}$. \\ Carmen Hernando ${ }^{6}$ - Piermaria Corona $^{3}$
}

Received: 5 June 2016 / Accepted: 22 November 2016 /Published online: 6 February 2017

(C) INRA and Springer-Verlag France 2017

\begin{abstract}
- Key message Fuel moisture and chemical content affecting live plant flammability can be measured through laboratory and field techniques, or remotely assessed. Standardization of methodologies and a better understanding of plant attributes and phenological status can improve models for fire management.
\end{abstract}

\section{Handling Editor: Barry Alan Gardiner}

Contribution of the co-authors Co-authors from CREA: contributed to writing the paper and specifically to sections 4.2 and 4.3.

Gavriil Xanthopoulos and colleagues from INIA: contributed to general drafting of the manuscript and in particular to section 3 with their expertise in flammability detection at multiple scales.

Jean-Luc Dupuy: contributed with general drafting of the manuscript and section 4.3.

Silvano Fares

silvano.fares@crea.gov.it

1 Council for Agricultural Research and Economics (CREA), Research Center for the Soil-Plant System, Rome, Italy

2 Council for Agricultural Research and Economics (CREA), Research Unit for Climatology and Meteorology Applied to Agriculture, Rome, Italy

3 Council for Agricultural Research and Economics (CREA), Forestry Research Centre, Arezzo, Italy

4 Ecologie des Forêts Méditerranéennes, Institut National de la Recherche Agronomique, Domaine Saint Paul, Site Agroparc, France

5 Hellenic Agriculture Organization "Demeter", Institute of Mediterranean Forest Ecosystems, Athens, Greece

6 Department of Silviculture and Forest Management, National Institute for Agricultural and Food Research and Technology (INIA)-Forest Research Centre (CIFOR), Madrid, Spain
- Context Wildland fire management is subject to manifold sources of uncertainty. Beyond the difficulties of predicting accurately the fire behavior, uncertainty stems from incomplete understanding of ecological susceptibility to fire.

- Aims We aimed at reviewing current knowledge of (i) plant attributes and flammability: fuel moisture and chemical content in leaves; (ii) experimental evaluation of flammability in the laboratory and in the field; and (iii) proxy evaluation of flammability: vegetation cover assessment at large scale, fuel seasonality, and biomass distribution using remote sensing and Light Detection and Ranging (LiDAR) techniques.

- Methods We conducted a review of scientific literature from the last two decades on the three selected issues, with a specific focus on the Mediterranean region.

- Results We have evidenced important knowledge gaps: (i) developing standardized methodologies for laboratory- and field-scale assessment of vegetation flammability; (ii) introducing reliable approaches to test the impact of biogenic volatile organic compounds on fire spread; (iii) improving the analysis of spatiotemporal changes in vegetation dynamics, acknowledging distinctive vegetation phenological status as a relevant driver affecting leaf biomass and moisture contents; and (iv) further exploring the processes that shape fuel dynamics to understand how fuel characteristics change over time and space.

- Conclusion We propose some improvements in the current knowledge of vegetation science and wildland fire ecology, aiming to generate more realistic models and effective planning in support of fire management in the Mediterranean basin.

Keywords Live fuel vegetation - Mediterranean forests · Biogenic volatile organic compounds · Plant moisture · Remote sensing $\cdot$ LiDAR 


\section{Introduction}

While human factors are known to be crucial drivers of wildfires in Mediterranean countries, climate forcing still represents the main determinant of wildfire ignition and spread (Bajocco et al. 2015; Barbati et al. 2015). Climate affects both the spatial distribution of vegetation types and their fuel characteristics and the conditions for fire ignition and propagation in terms of weather patterns and extremes (temperature, relative humidity, wind, precipitation, drought). Drought in particular affects live and dead fuel moisture content, thus influencing fire regimes. As a consequence, a significant correlation between wildfires and the phenological status of vegetation has been widely observed in southern Europe (Moreira et al. 2011; De Angelis et al. 2012).

Warmer and drier future climates will exacerbate fire severity, intensity, and frequency for the fire-prone ecosystems, as those in the Mediterranean area (Lindner et al. 2010; Kolström et al. 2011; Fares et al. 2015). In this region, fire danger is likely to increase (Moriondo et al. 2006), and forest fires will become an even larger threat to forestry, farming, and human well-being in rural areas (Lindner et al. 2010). In this context, attributes of live vegetation and the capacity to properly characterize live fuel become crucial for effective management planning (Fig. 1) aimed at mitigating fire danger and maintaining the capacity for Mediterranean forests to provide ecosystem services (Tilman et al. 2000; Keane 2013). While a general classification may consider fuel loading or biomass per unit area as one of the main fuel attributes, it is evident that species-specific characteristics of vegetation may affect flammability (Dimitrakopoulos 2001; Salvati and Ferrara 2015). In the last two decades, an increasing number of studies have been carried out on such issues in Mediterranean countries (Fig. 2), mainly in the West and Central areas of the North Mediterranean region. Based on these premises, growing attention is devoted to the intimate relationship between vegetation characteristics, fuel attributes, and local (or regional) changes in climate regimes when developing realistic models supporting fire management.

The purpose of this review is to contribute to these important and sometimes undervalued practices for describing and characterizing live vegetation as potential fuel. The rationale of this work is to (1) review the most important findings from scientific literature from the last two decades to highlight those traits of live Mediterranean vegetation which most likely relate to flammability such as chemical and moisture content; (2) discuss the main approaches to measure these vegetation properties mostly based on experimental measurements in the laboratory and in the field, up to local/regional studies using remote sensing and Light Detection and Ranging (LiDAR) techniques; and (3) identify knowledge gaps on the most relevant issues that require further investigation based on integrated approaches derived from both geoecology and forest science.

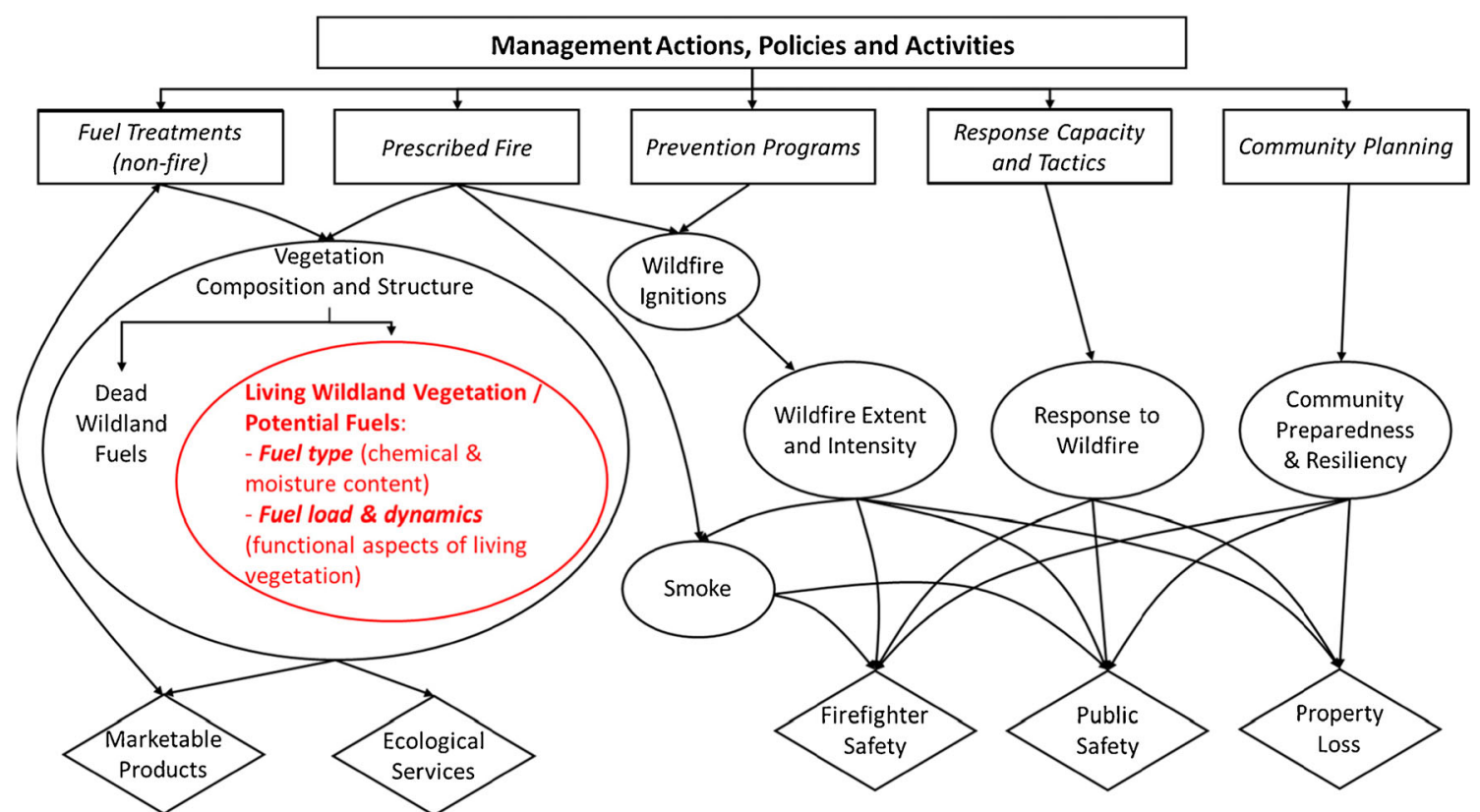

Fig. 1 Simple conceptual model of the major anthropogenic factors involved in wildland fire management, principal interacting processes, and values affected by fire. Adapted from a report of the US National Science and Analysis Team (NSAT 2012), the model shows in red the fire management activity that is the object of our discussion 


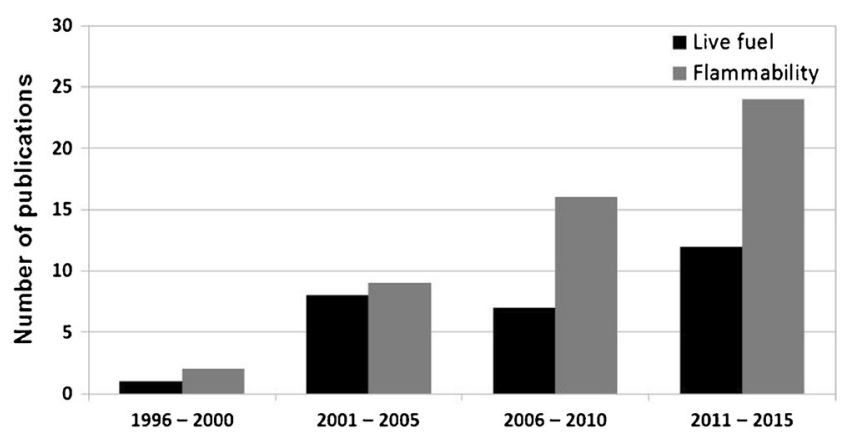

Fig. 2 Number of scientific publications found on Scopus from 1996 to 2015 with the following search criteria: (wildfire OR forest fire) AND Mediterranean AND (flammability OR live fuels OR live vegetation fuels). The survey was conducted on December 8, 2015

\section{Attributes of live Mediterranean vegetation as potential fuel}

Live fuel is characterized by vegetation attributes, which affect plant flammability (Gill and Zylstra 2005). These include ecosystem-specific biomass, spatial arrangement, moisture content, and chemical composition. Such properties are not constant over time, but change according to the phenological cycle. Albeit often undervalued under the perspective of wildfire science, phenological status, intended as the timing of recurring biological events in response to biotic and environmental interactions, is a key factor influencing fuel characteristics, in terms of both availability and moisture content (Bajocco et al. 2015). Therefore, flammability of forests varies during the year due to changes in chemical composition of the fuel, moisture content, leaf biomass, and the proportion of dead and live fuel. Leaves with higher surface area-tovolume ratios ignite more quickly due to a relatively larger contact area for pyrolysis to take place (Gill and Moore 1996). Larger leaves create open, low-bulk-density fuelbeds that allow greater airflow and burn more rapidly, especially in broadleaf forests (Page et al. 2012). In general, long, curling leaves burn faster with greater intensity (Clarke et al. 2014). Chemical and moisture content are relevant intrinsic features of living plants, which deserve more attention.

\subsection{Chemical content of plant material and flammability}

On a global basis, live biomass stores $42 \%$ of the total carbon stock (Pan et al. 2011). Combustion is an exothermic reaction in which gaseous, liquid, and solid materials containing different amounts of carbon are oxidized at high temperatures. Compared with coal, plant biomass contains less carbon and more oxygen. Therefore, biomass combustion generates less energy (roughly $16,000 \mathrm{~kJ} \mathrm{~kg}^{-1}$ ) than charcoal $\left(31,000 \mathrm{~kJ} \mathrm{~kg}^{-1}\right)$. Despite the chemical content, the temperature reached during the combustion also determines the final combustion products: efficient combustion results in higher emissions of $\mathrm{CO}_{2}, \mathrm{NO}_{x}$, and water, while lower temperatures still allow production of biogenic volatile organic compounds (BVOCs), $\mathrm{CO}, \mathrm{CH}_{4}$, and particles. Fuel consumption broadly follows biome distributions with low biomass biomes such as grasslands and savannas burning less fuel than high biomass forest types (Van der Werf et al. 2010).

Wildland fires have the potential to release massive amount of carbon into the atmosphere. The majority of carbon emitted from forest fires is released as $\mathrm{CO}_{2}$ with global estimates close to $2000 \mathrm{Tg}$ (C) year ${ }^{-1}$ (Van der Werf et al. 2010). The chemical content in leaves is species-specific and determines different properties of flammability, which include ignitibility (timing of the fuel ignition), combustibility (how well it burns), and sustainability (for how long it burns) as discussed by Gill and Zylstra (2005). Ciccioli et al. (2014) argue that if fuel contains only $\mathrm{C}$ and $\mathrm{H}$, then $\mathrm{CO}_{2}$, water, and $\mathrm{NO}_{x}$ are formed. However, fuel combustion produces a higher number of compounds in open forests, depending on the type of fuel and its content of $\mathrm{C}, \mathrm{O}, \mathrm{H}, \mathrm{N}$, and S. Lignin, tannins, and ammonium phosphates (which contain nitrogen and phosphorous) are known to reduce combustibility by promoting char formation during the depolymerization phase (pyrolysis) of a fire (Scarff et al. 2012). Different contents of lipids, phenolic compounds, isoprenoids, fatty acids, resin acids, steryl esters, sterol, aminoacids, proteins, and waxes in leaves can produce a multitude of gases and particles (Rowell et al. 2012).

A peculiar role, often undervalued with respect to flammability, is due to the BVOCs that most vascular plants produce and emit to the atmosphere. BVOCs are molecules produced in leaves, flowers, and roots. Isoprenoids (isoprene, monoterpenes, sesquiterpenes) are the most reactive BVOCs produced by plants and are often defined as constitutive since their biosynthetic formation pathway is often linked to photosynthesis as in the case of isoprene. These highly volatile compounds are emitted at an estimated rate of $1-1.5 \mathrm{Pg} \mathrm{C}$ per year on a global scale (Guenther et al. 2006). BVOC emissions from vegetation fires represent a very small fraction of the overall $\mathrm{CO} / \mathrm{CO}_{2}$ emissions from fires, accounting for between 20 and $40 \mathrm{Tg} \mathrm{year}^{-1}$, and are lower than VOC emissions associated with the production and use of fossil fuels (77.4 $\mathrm{Tg}$ year $^{-1}$ ) (Reimann and Lewis 2007). However, some studies showed that flammability is influenced by the content of BVOCs in leaves, with ignition occurring earlier in BVOC storing and/or emitting species (Owens et al. 1998; De Lillis et al. 2009). A recent study by Chetehouna et al. (2013) calculated that emitted BVOC from Rosmarinus officinalis can lead to an accelerating wildfire especially when BVOCs volatilized at high temperatures accumulate in canyons. This feature is also recalled in the "thermochemical hypothesis" from Courty et al. (2014), who also showed that gases emitted by heated $R$. officinalis needles can be ignited with a pilot flame. Barboni et al. (2011) highlighted the fact that Mediterranean trees emitting BVOC have the potential to accumulate in the vicinity of the fire front and therefore initiate an eruptive fire 
with dramatic risks for firefighters. Based on pyric properties, eight Mediterranean tree species were divided in four categories of flammability and the most flammable species are isoprenoid emitters such as Pinus halepensis, Pinus brutia, and Quercus ilex (Dimitrakopoulos 2001).

While the percentage fraction of carbon in the dry vegetation has limited variations among species ranging from 45 to 55\% (Urbanski et al. 2009), BVOC emissions reflect withinspecies differences. For instance, emissions from boreal forest fires were representative of the majority of conifers in Northern Canada containing high levels of monoterpenes in their needles and bark (Simpson et al. 2011). In savannah fires, low emission rates were recorded, since this ecosystem is characterized by the predominance of Gramineae, which are known to be poor isoprenoid emitters (Kesselmeier and Staudt 1999). Although no focused studies are available for Mediterranean plants, Mediterranean tree and shrub species were found to produce many BVOC species (Fares et al. 2009). The possibility that BVOCs enhance plant flammability is a tenable theory that deserves further investigation (Owens et al. 1998).

\subsection{Moisture content of live vegetation and flammability}

Fire potential is related to fuel moisture. Higher leaf moisture concentrations will lower the ignitibility by requiring more energy for water evaporation and preheating of the fuel. Etlinger and Beall (2004) showed that the heat release rate of trees is more influenced by moisture than any other chemical characteristic. Leaf relative water content (RWC) is an indicator that can be used to evaluate plant water status. Peñuelas et al. (2004) showed that photosynthetic rates and stomatal conductances decreased as leaf RWC diminished in rain-fed Phillyirea angustifolia plants. Live foliar moisture content changes not only because water amount in foliage changes but also because the dry mass of leaves can change over the season. Jolly et al. (2014) showed that changes in the mass and composition of dry material over the season better explain changes in live foliar moisture content than the water stress itself for pine canopies.

Regional climate modeling has been frequently used for simulating high-resolution physical processes in the atmosphere, soil, and vegetation (Thompson and Calkin 2011). Specific climate models can be implemented to evaluate wildfire potential by either assessing meteorological conditions for computation of fire indexes or predicting soil moisture as a direct measure of fire potential (Moriondo et al. 2006). Two popular fire potential indexes, based on meteorological conditions and focused on drought, are the Drought Code of the Canadian Fire Weather Index and the Keetch-Byram Drought Index (KBDI). They have been shown to correlate well with the moisture content of Mediterranean shrubland species (Pellizzaro et al. 2007), while the KBDI has also been shown to correlate quite well with living plant water stress as measured through plant water potential (Xanthopoulos et al. 2006). A similar conclusion was found by Mavrakis and Salvati (2015) who quantified meteorological conditions and mega-fire density over the last two decades in Greece. Soil aridity conditions determined by long periods of drought were identified as significant predictors of wildfire occurrence (based on frequency) and spreading (based on the surface area burnt per fire) (Gudmundsson et al. 2014).

Live fuel moisture content (LFMC) is a metric responsive to long-term climate and plant adaptations to drought used in a number of fire modeling systems (Andrews et al. 2003) as a key factor for the ignition and propagation of fire. At stand level, empirical models or correlations have been proposed with the aim at predicting the moisture content of shrubland fuel beds (Viegas et al. 2001; Castro et al. 2003), but such predictions suffer from a lack of process-based models to predict the moisture content of shrubland fuel beds. In addition, the water content of plant tissues is not a typical variable in ecophysiological models that frequently use water potential to assess water status.

At the landscape level, LFMC can also be estimated using remote sensing (Verbesselt et al. 2003; Yebra et al. 2013). Empirical methods have been used to investigate the relationship between fuel moisture, vegetation greenness indexes such as the normalized difference vegetation index (NDVI) or its change over time and space (Chuvieco et al. 2002), and surface temperature (Sow et al. 2013). Some authors used ad hoc water stress indexes like the Moisture Stress Index or the shortwave infrared water stress index that exploit the water content-driven spectral behavior of vegetation in the middle infrared wavelengths (Hunt and Rock 1989; Fensholt and Sandholt 2003; Olsen et al. 2015). However, according to Yebra et al. (2013), empirical relationships between LFMC and remotely sensed data often have the drawback of being site-specific, while the selection and parameterization of physically based algorithms are far more complex. Many challenges remain in quantifying error of remote sensing-based LFMC estimations and linking LFMC to flammability and risk.

\section{Experimental evaluation of live vegetation flammability}

In order to characterize fuel attributes, particular attention should be given to fuel flammability (Xanthopoulos et al. 2006; Corona et al. 2014). Flammability can be experimentally assessed through laboratory or field experiments, at different organizational levels (organ, plant, community).

Flammability is experimentally assessed by burning fuels in the laboratory, either in the form of discrete elements (leafs, twigs, etc.) or as a fuel bed (Fernandes and Cruz 2012). 
Although several authors have emphasized the difficulty of evaluating live vegetation flammability, different methods have been used to evaluate experimentally some of its characteristics (Etlinger and Beall 2004; Madrigal et al. 2009). Traditionally, experiments have been conducted with Mediterranean species by means of epiradiators (Pausas et al. 2012; Ganteaume et al. 2013) or radiant heaters (Dimitrakopoulos and Papaioannou 2001), measuring time to ignition of the samples at a standard heat flux (Fig. 3). Hachmi et al. (2011) proposed a flammability index of Moroccan species, integrating time to ignition, time of combustion, and flame height obtained in an epiradiator. Madrigal et al. (2013) have developed a bench-scale method with a mass loss calorimeter to estimate flammability attributes (time to ignition, peak heat release rate, mass loss rate, average effective heat of combustion, and total heat release) and a moisture analyzer to evaluate fuel moisture content. Both epiradiators and mass loss calorimeters have been used by Della Rocca et al. (2015) to characterize the flammability of Cupressus sempervirens.

At whole-plant level, flammability of live vegetation has been assessed in indoor laboratory conditions using a newly developed laboratory fire protocol to determine heat release rate (Etlinger and Beall 2004). Chetehouna et al. (2014) applied a Froude-scaling approach to laboratory emissions of
BVOCs of $R$. officinalis to evaluate concentrations of these compounds at field scale. Experiments in an outdoor wind tunnel, as a surrogate of field conditions, have been carried out using a flaming point ignition source (Marino et al. 2012). In a complementary work, Madrigal et al. (2012) evaluated the effect of the different measurement scales and methodological approaches used to determine the flammability of live vegetation. Ignitability was highly dependent on the type of ignition source, combustibility was more dependent on the dead fraction than on live plant part characteristics, sustainability was mainly related to physical characteristics, and consumability of residual mass fraction was similar at both scales.

Laboratory observations need to be able to simulate possible field-scale dynamics in order to avoid unrealistic parameterization of live fuel moisture effect on fire sustainability and rate of spread in empirical models (Anderson et al. 2015). The rate of spread was found to be halved by an increase in live moisture content of different fuel beds from 50 to $180 \%$ (Rossa et al. 2016). This effect, especially at higher moisture contents, was weaker than that predicted by theoretical formulations and from studies in mixtures of dead and live fuel, thus suggesting that live fuel affects fire spread rate through properties other than moisture content. Fernandes and Cruz (2012) also highlighted that the assessment of flammability in the laboratory is limited by various factors: scale,
Fig. 3 a Epiradiator used to test cypress flammability by Della Rocca et al. (2015). b Mass loss calorimeter used by Madrigal et al. (2009) to evaluate forest fuel flammability and combustion properties. c Ignition apparatus used in the flammability tests of Mediterranean forest fuels by Dimitrakopoulos and Papaioannou (2001). d Flammability test in outdoor wind tunnel for shrub fuel, with detail of the epiradiator and the flaming point-ignition source used by Marino et al. (2012) to test the effect of different treatment types on fire initiation risk

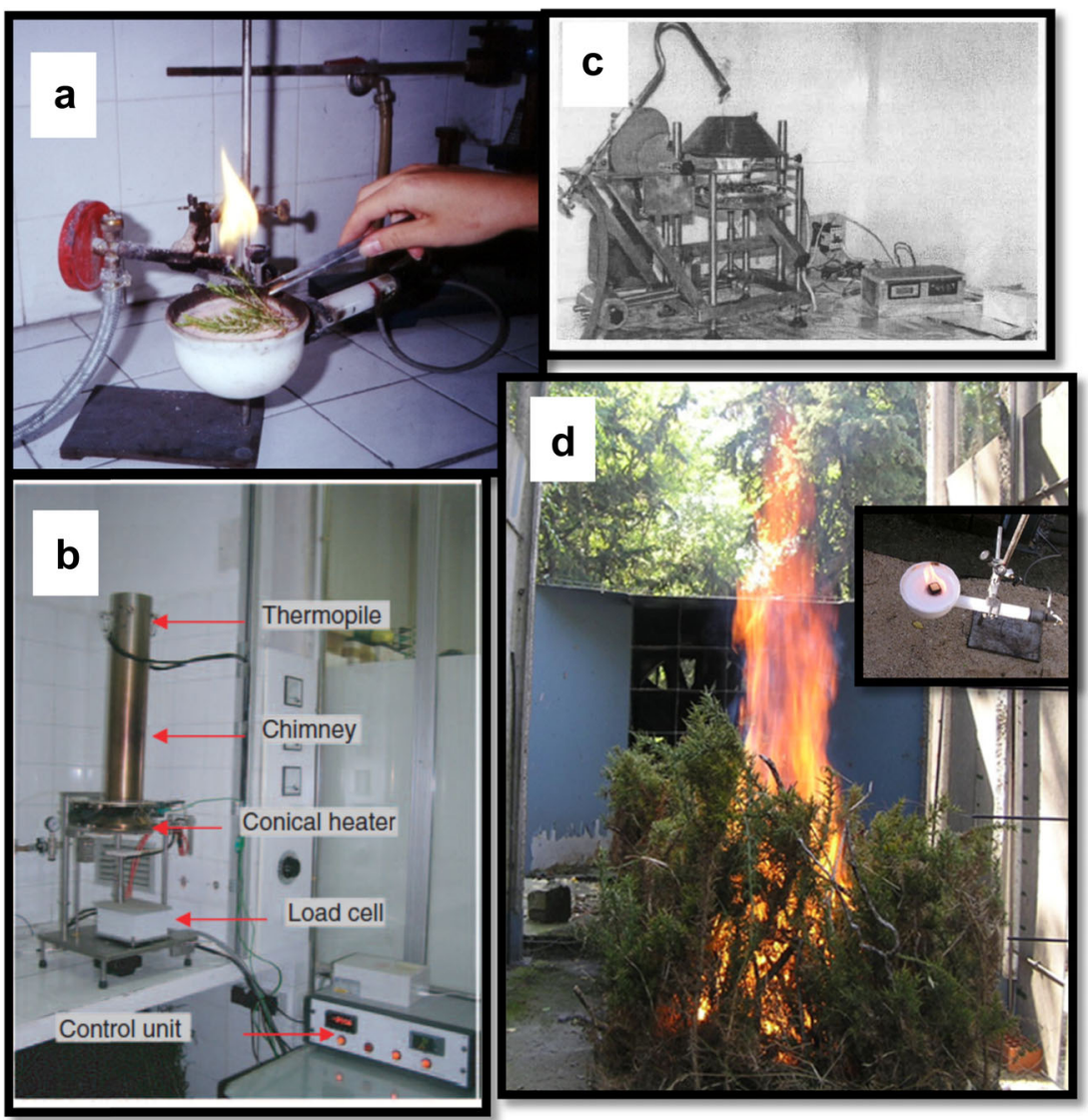


replication of the complexity of fuel composition and physiological conditions, and plant exposure to heat. In order to more closely match the natural fire conditions, Dimitrakopoulos et al. (2010) have tested the in situ flammability of the annual herbaceous species Avena barbata with a drip torch during two fire seasons, with simultaneous monitoring of the weather conditions.

Unfortunately, few studies have measured the flammability of whole woody plant in natural conditions, and none in the Mediterranean region. According to Schwilk (2015), the difficulty of large-scale crown fire experiments is the reason why flammability is inferred from trait measurements and general models of flammability. In this respect, Fernandes and Cruz (2012) suggested physical-based fire models as the best route to understanding plant flammability. More recently, Finney et al. (2015) challenged numerical modeling suggesting missing physical components of wildfire spread, highlighting that wildfire spread derives from the coupling between flame dynamics induced by buoyancy and fine-particle response to convection.

Measurement of gaseous emissions is an indirect way to test flammability. Smog chambers in combustion facilities have been recently used by Lusini et al. (2014) for a range of Mediterranean plants. These allowed a study of the three phases characterizing wildfires: pre-combustion, when wood starts to dehydrate releasing water vapor and BVOCs; (ii) ignition, when high temperature leads to an exothermal reaction and release of other BVOCs, $\mathrm{CO}_{2}, \mathrm{CH}_{4}$, formaldehyde, and other oxygenated VOCs; and (iii) combustion which produces large amounts of carbon dioxide, inorganic gases like $\mathrm{NO}_{x}$ and $\mathrm{SO}_{2}$, and pyrogenic VOCs like alchenes and flames which release most of the heat (Andreae and Merlet 2001). Page et al. (2012) also showed that isoprenoid emissions were correlated with the flammability of Pinus contorta leaves, which had been attacked during the previous year by mountain pine beetle inducing changes in the foliage water content and chemical composition. The three phases of forest fires were also recently investigated by Grootemaat et al. (2015) using individual leaves from Australian tree species in a muffle furnace and found that different combinations of morphological and chemical leaf properties underpinned the interspecific variation in decomposability and flammability of the studied species. While combustion facilities are ideal to test the capacity of plants to emit gaseous compounds in response to forest fires, when wildfires occur rapidly, the resulting emissions are representative of all the combustion processes, which occur simultaneously. Therefore, a top-down approach with the aim at estimating emissions of trace gases is the most valuable approach. This implies measuring gas concentrations in vegetation combustion plumes (Urbanski et al. 2009) and estimating fluxes by concentration gradients measured on site or with flights around the burning area (Akagi et al. 2011).

While laboratory tests can provide detailed and quantitative results in terms of biomass burned and gaseous emissions,
Ciccioli et al. (2014) argued that results obtained from the analysis of live leaves are still not fully definitive. In real field conditions, highly volatile isoprenoids are emitted as leaves are exposed to high temperatures, as also hypothesized by Chetehouna et al. (2013) and demonstrated empirically by Courty et al. (2014). Thus, their intrinsic flammability may be masked by the dynamic of a fire event, because prior to leaf ignition, the isoprenoid pool may already be depleted when the leaves are exposed to pre-heating and pre-ignition temperatures (Greenberg et al. 2006). BVOCs accumulating in canyons and in the vicinity of the fire front may favor eruptive fires (Barboni et al. 2011). Conversely, when leaves are directly and suddenly exposed to flame, high isoprenoid contents may facilitate flammability. As discussed in a recent review by Varner et al. (2015), the metrics evaluated by flammability studies are generally consistent, but comparison across methods is challenging. Even when studies follow a consistent method, there are cases of intraspecific differences, as in the case of a phenotipic plasticity, or lack of experimental repeatability.

\section{Proxy evaluation of live vegetation flammability}

In order to dynamically characterize and model fuel attributes up to landscape scales, vegetation cover quality in terms of fuel type and fuel load (Bajocco et al. 2012) and functional aspects of live vegetation/potential fuel have to be considered (De Angelis et al. 2012).

\subsection{Large-scale vegetation cover assessment}

The vegetation cover of a territory (e.g., in terms of land or ecosystem productivity) is considered one of the most sensitive factors to landscape dynamics and transformations in the Mediterranean basin (Pettorelli et al. 2005) and may be considered as a proxy for the "green" component and the related fuel potential.

In order to support a general spatial flammability assessment, independent of the condition in which a particular forest is at a particular moment, Xanthopoulos et al. (2012) ranked the flammability of 60 vegetation types, associating them to the corresponding European Forest type classification for Europe and North Africa, based on questionnaires answered by 20 forest fire experts from 14 countries. The vegetation quality index (VQI) is a comprehensive indicator system which includes different components assessing vegetation quality (i.e., degree of vegetation cover, fire risk, protection from soil erosion, drought resistance of vegetation) quantified on the basis of a weighted score depending on the different land use types. The VQI has been extensively validated in the field and identifies vegetation spatial patterns based on place- 
specific social and environmental factors (Salvati and Ferrara 2015).

The main operational outcome of the abovementioned methodologies is the stratification of fire hazard in terms of forest flammability potential assessed from forest type maps, which may be available even over very large areas. The Coordinated Initiative on the Environment (CORINE) Land Cover maps were extensively used to assess flammability potential (and its change over time) according to the abovementioned approaches (Corona et al. 2014). An improved effort by official sources (e.g., European Environment Agency, Joint Research Centre, Eurostat) is especially needed to produce diachronic layers with the highest spatial precision and comparability (Salvati and Ferrara 2015), with the aim to limit the impact of data inaccuracies and between-source differences.

However, such approaches should be regarded as producing structural indicators of vegetation/fuel quality. These indicators are not suited to quantify functional characteristics of fuel and its dynamics over time due to environmental disturbances (Bajocco et al. 2012). In this contrast, multitemporal satellite images can provide useful information in a timely and cost-effective fashion.

\subsection{Use of remote sensing for detection of fuel dynamics}

Traditionally, live fuels have been mapped by field survey, a time- and cost-consuming activity. For this reason, researchers have spent the last decades investigating the potential role of remote sensing in vegetation science and environmental applications. Remote sensing can offer information on ecosystem phenology and productivity over several temporal scales and continuous spatial coverage. Space-borne optical sensors, such as NASA-MODIS, provide daily measurements of a variety of biophysical satellite-based parameters of the land surface (Friedl et al. 2002). These earth observation systems examine coarse-scale phenomena that allow retrievals of wholesystem phenological metrics, such as the timing and magnitudes of greening, peak activity, and drying phases of the growing season (Ma et al. 2013).

At this geographical scale, the spatio-temporal dynamics of the vegetated land surface is often represented by the multifactorial notion of "land surface phenology," as the remotely sensed phenology deals with mixtures of land covers and vegetation (de Beurs and Henebry 2005; Brown et al. 2010). Yebra et al. (2013) discuss the potential of using remote sensing techniques to determine live fuel moisture. The authors conclude that changes in moisture have both direct (liquid water absorption) and indirect (pigment and structural changes) impacts on spectral reflectance, and they encourage the use of physical model-based methods applied to coarse-resolution data covering the visible, near infrared, and/or shortwave infrared regions of the spectrum rather than empirical relationships.

Vegetation functioning responds faster to environmental change and variability than vegetation structure and composition; therefore, a high potential exists for characterizing, classifying, and mapping fuel based on remotely sensed vegetation dynamics. A number of studies have used remotely sensed indexes, such as the NDVI, for the monitoring of vegetation dynamics from regional to global scales (e.g., Jeong et al. 2011; Fensholt et al. 2012; Ivits et al. 2012).

However, in order to improve the capability of remote sensing indicators to capture ecosystem functional dynamics, future research should go beyond the traditional use of NDVI as biomass proxy and identify fuel categories on the basis of their dynamic patterns over time and space. Variations in NDVI values demonstrated to be indicative of variations in moisture content, nutrient availability, plant disease, and other stress factors; these are in turn indicators of a marked vulnerability of vegetation to fire (Fiorucci et al. 2007). Over the years, the use of seasonal NDVI profiles to assess vegetation fireproneness has been proposed by many authors (see Lasaponara 2005). Accordingly, the fuel phenological status, in terms of seasonal vegetation productivity and foliar greenness, represents the main proxy for potential fuel load and flammability at a coarse scale (De Angelis et al. 2012).

As for remotely sensed fuel seasonality, several authors proposed different methods to derive regional phenological classification of vegetation. White et al. (2005) proposed a geographic framework for studying global climate change and developed a pheno-region database. They used 8-km AVHRR NDVI time series (1982-1999) together with an eight-element monthly global climatology to generate global pheno-regions with a minimized probability of non-climatic forcing. Hargrove et al. (2009) derived 15 phenological ecoregions based on a hierarchical clustering of similarities in 5 years (2002-2006) of cumulative MODIS NDVI data. Ivits et al. (2012) explored a long-term trend of vegetation growth over Europe for 1982-2006 by analyzing remote sensing data at pixel level. The authors assessed which component of the seasonal timing of vegetation growth changes across Europe can be attributed to climate change and identified those change pixels that can be sufficiently explained by climate variables alone or that may require additional data. Clerici et al. (2012) explored the use of MODIS NDVIderived phenology metrics for the identification and classification of Forest General Habitat Categories (FGHC) in Europe. On the contrary, other authors highlighted the specific connection between living vegetation phenology as potential fuel and wildfire patterns. Chèret and Denux (2007) analyzed the ability of SPOT-VGT NDVI multitemporal data to assess vegetation fire susceptibility; they calculated a yearly index from NDVI values measured at given times in the annual vegetation cycle to represent its drying intensity in summer 
and identified areas where natural vegetation reaches the highest level of combustibility during the driest period of the year. Bajocco et al. (2010) quantified the explanatory power of multitemporal NDVI profiles on the fire regime characteristics of the vegetation types of Sardinia (Italy) pointing out that the annual variability of fuel greenness mainly influences wildfire frequency, mean size, and date of occurrence, while the annual fuel amount is mainly correlated with the large fire events. Finally, De Angelis et al. (2012) and Bajocco et al. (2015) used MODIS NDVI phenological metrics to classify the coarse-scale vegetation of Sardinia (Italy) into phenological clusters showing uniform behavior in relation to fire ignition. Based on the study from Bajocco et al. (2015), Fig. 4 shows a map of the Sardinia region with fire occurrences and corresponding phenological fuel classes. In this general overview, the relationship between the dates of onset/offset of (remotely sensed) vegetation and forest fire dates remains unexplored, notwithstanding the key role of this aspect under climate and global change scenarios. This research gap implies the urgent need to develop proper algorithms able to extract phenological metrics, reliable across different ecosystems, and that can be used under different wildfires regimes.

\subsection{LiDAR techniques for monitoring and characterizing vegetation fuel}

Because optical images are not sensitive to below-canopy forest attributes, they have limited ability to detect vertical fuel distribution, understory characteristics, and the canopy base height of fuels (Arroyo et al. 2008). Alternatively, Light Detection and Ranging (LiDAR) is a promising technology for generating reliable representations of the horizontal and vertical forest structures, due to its capacity for scanning wide areas and producing precise vertical and horizontal estimates of forest attributes. Of importance, airborne LiDAR, or airborne laser scanning (ALS), has been used extensively for forestry applications, and various studies highlight that fire behavior modeling can benefit from such a technology because, in combination with optical remotely sensed images,

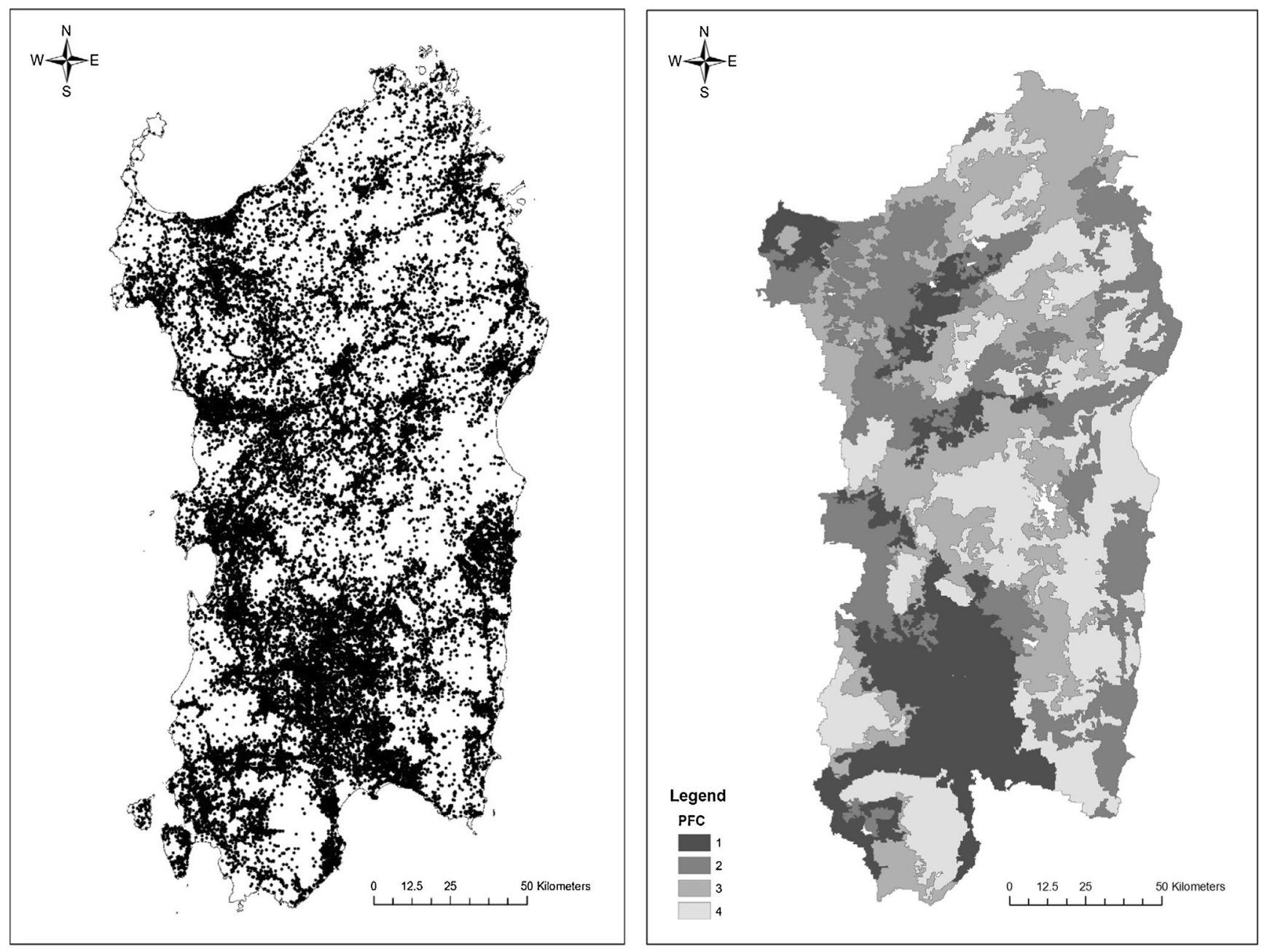

Fig. 4 Left panel: distribution of forest fires from 1995 to 2013 in Sardinia Region (Italy). Right panel: distribution of Phenological Fuel Classes based on previous paper by Bajocco et al. (2015). PFCs follow a gradient from PFC1 (finest fuel class) to PFC4 (coarsest fuel class) 
it improves estimation of forest fuel variables (Andersen et al. 2005; Mutlu et al. 2008; Erdody and Moskal 2010).

Several studies, conducted mostly in temperate and boreal forests of Europe and North America, indicate the potential of discrete return ALS for estimating tree or forest variables as components of live vegetation fuels (Corona et al. 2012; Montaghi et al. 2013). For example, tree height can be readily estimated from the ALS point cloud. Crown base height, a critical fuel property used to estimate surface and crown fires, can be estimated using automated, individual tree recognition methods that extract single tree locations and delineate full crowns. So far, the accuracy of single tree estimates was found to be greater for coniferous than for broadleaved forests, because coniferous crowns are usually easier to detect. Crown variables such as depth, size (as diameter, area, or volume), biomass, or bulk density (foliage biomass divided by the crown volume) can be empirically estimated from ALS data with parametric methods such as allometric regression models (Fig. 5) or non-parametric (or mixed) approaches based on data mining techniques such as support vector machines (SVM) or classification and regression trees (Chirici et al. 2013).

ALS technology appears more limited for predicting the characteristics of understory and midstory fuels (grass, shrubs, small trees), especially for low-vegetation canopy heights (Riaño et al. 2007). The extraction of data on understory vegetation (e.g., percentage cover and height of the shrub layer) has been investigated in only a few studies (Riaño et al. 2003). Promising approaches based on the decomposition of the main Gaussian components of the signal have been proposed when full-waveform raw ALS data are available (Hug et al. 2004).
Laser applications proved their capability for mapping fuel types. In an exploratory work, Seielstad and Queen (2003) empirically demonstrated that the profiles of laser returns, as a function of height above the estimated median ground surface, were able to characterize fuel types 8 (closed timber litter) and 10 (timber) of the Anderson nomenclature system (Anderson 1982). Mutlu et al. (2008), Koetz et al. (2008), and García et al. (2011) investigated the possibility of using the combination of ALS and multispectral optical imagery for mapping fuel models. Mutlu et al. (2008) generated a LiDAR-derived multiband dataset from scanning data that was used in combination with multispectral Quick Bird bands to achieve a per-pixel discrimination of Anderson models using traditional supervised parametric classifiers. A similar approach was used by Koetz et al. (2008) to classify general land cover classes with SVM using a combined dataset with images from an AISA/Eagle imaging spectrometer and six gridded ALS variables. García et al. (2011) used SVM to classify a multidimensional dataset created with the four raw multispectral bands, nine additional indexes from an Airborne Thematic Mapper, and indexes calculated from ALS data for ten land and forest cover types. Forest types were then further classified accordingly to the Prometheus fuel model system (Chuvieco et al. 2003) with a decision tree applied to ALS returns. However, Chirici et al. (2013) suggested that the estimation of canopy and ground fuel characteristics on the basis of ALS height measurements should be preferred to the direct derivation of fuel type maps based on an aggregated system of nomenclatures since it can be used to derive wall-to-wall maps of fuel properties over the landscape.

Terrestrial LiDAR systems have recently emerged as promising tools for canopy leaf biomass or surface area estimation
Fig. 5 Examples of selected metrics from canopy height model (CHM) derived by airborne laser scanning showing good relationship with average crown depth, a major live vegetation feature influencing fire behavior, as assessed in conifer (a) and deciduous broadleaved (b) stands in Casentino valley (Central Italy). Original data collected by P. Corona a



b

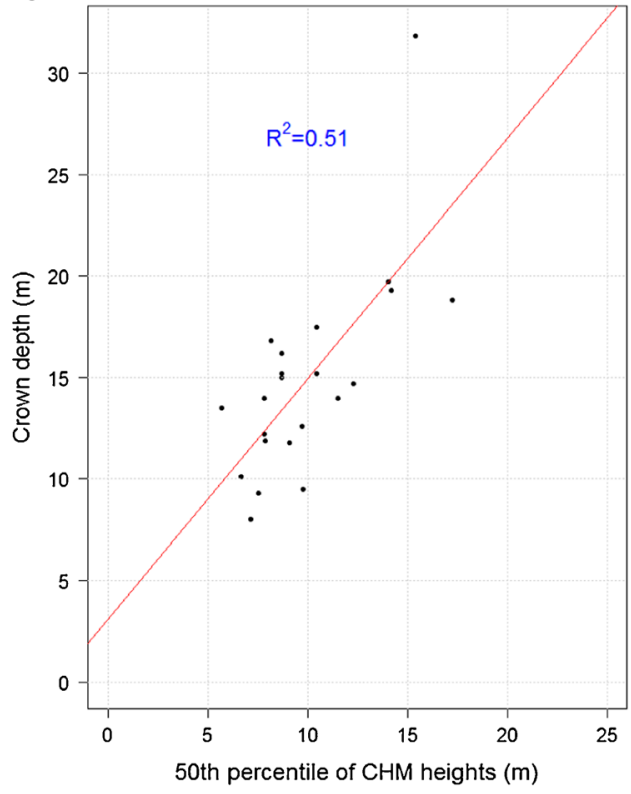


at the scale of trees or forest plots. Such measurements at plot scale are required to get reference data for methods operating at larger scales or for monitoring vegetation fuels at specific locations. The distribution of terrestrial LiDAR returns can be used to estimate foliage density indices in voxels (Côté et al. 2011). These indices can be specifically computed for the leaves when the intensity can be used to distinguish leaf from wood returns (Béland et al. 2014) or finer elements from larger ones (Seielstad et al. 2011). Direct measurements of foliage density (Hosoi and Omasa 2006, 2007; Béland et al. 2014) have been used successfully at tree scale but require voxelization of the scanned scene at 0.001 to $0.1 \mathrm{~m}$ and multiple scans for a single tree. This is time-consuming in terms of measurements and post-processing and may be considered to be a limitation for operational use. Seielstad et al. (2011), therefore, used a calibration approach to estimate branch biomass from scans and proposed to use randomized branch sampling to extrapolate to trees. Skowronski et al. (2011) used upward sensing profiling and calibrated it at stand scale using an inventory-based approach. This method provides bulk density profiles at stand scale, but requires calibration from an existing inventory and the destructive sampling of trees to establish allometry. Also, it does not provide a 3D biomass distribution. Recently, Pimont et al. (2015) proposed an original calibration procedure of the LiDAR point density with foliage biomass measured in a few tens of sample volumes of canopy foliage $(\sim 0.2 \mathrm{~m} 3$, branch scale). The calibration allowed an estimation of foliage biomass 3D distribution at the plot scale from a few LiDAR scans in a Quercus pubescens stand. LiDAR-predicted bulk density vertical profiles of foliage compared well with inventory-derived ones, but further research is needed to separate the returns from leaves as opposed to trunks and branches. The calibration is specific of the foliage morphology at the scale of the calibration volume; therefore, the method needs to be applied to a diversity of species to confirm this promising approach.

\section{Conclusions}

Laboratory and field observations are key means to characterize live fuel for the management of wildland fires. We list the research needs emerging from this review.

- Inter-specific leaf/plant trait variability. While certain features are relatively homogeneous among forest species (e.g., carbon content in leaves), other variables still deserve in-depth investigation. For example, an integrated database collection of quantitative information of plant trait emissions is particularly important to estimate the potential role of vegetation in emissions during forest fires. Forest fire models proved to be realistic only when both physical (e.g., wind, slope, moisture content) and ecological approaches were carefully taken into account (Weise et al. 2005; Zhou et al. 2005), and only in the last decade did experimental evidences from the laboratory or in the field provide useful parameterization (Marino et al. 2012; Fernandes and Cruz 2012). This ecosystem approach may inform forest planners on the most suitable forest species for producing an overall decrease in the risk of fire for a fire-prone environment.

- Lab assessment of vegetation flammability. According to the previous point, developing commonly agreed standardized methodologies for the lab assessment of vegetation flammability is highly desirable.

- BVOC. These reactive compounds are still poorly investigated, although different patterns of BVOC production and emission have been correlated with flammability. As reviewed by Ciccioli et al. (2014), a viable approach would be to assign emission factors based on plant functional types, also considering that few quantitative information is available and it is not possible to perform a detailed emission assessment for every different forest ecosystem.

- Scaling approaches. While plant-specific experiments inform on mechanisms, studies that approximate field composition (via species mixtures) and structure are highly encouraged. In particular, the role of fuel moisture on the rate of fire spread in forests has not been sufficiently evaluated. Unexplained divergences between controlled laboratory conditions and field conditions suggest that further experimental research is highly desirable.

- Fuel phenology. We showed that vegetation phenological status represents a main driver, too often undervalued by wildfire science, affecting fuel load and flammability. However, any investigation over large areas requires the ability of capturing spatio-temporal changes in vegetation dynamics. Understanding the spatial distribution of vegetation dynamics (based on, e.g., the timing of fuel availability) may be key to planning effective firefighting and prevention strategies (Bajocco et al. 2015), since regions with similar fuel phenology patterns, and hence with similar fire incidence, are regions where similar management policies should be applied (Curt et al. 2013). NDVI multitemporal profiles may represent a suitable basis for the development of a regional-scale framework for fire ignition risk and fire prediction models. In addition, remotely sensed phenological data may also have additional value for various wildfire-oriented applications related to land surface monitoring and assessment (Nemani et al. 2009), including drought monitoring as well as ecological modeling of the impact of global change on burning patterns (Morisette et al. 2009; Thonicke and Cramer 2006).

- Fuel dynamics. Most current operational fire prediction systems use a set of static fuel types as inputs and specific sub-models to determine fuel available for combustion. 
However, fuel dynamics mean that some fuel attributes are continuous properties that cannot easily fit to a limited number of fuel types in empirical and semi-empirical models. Physics-based models of flammability have the potential to deal with a continuous range of fuel properties and as such should allow better understanding of the impact of fuel dynamics on wildfire spread. As stressed by Keane (2013), there are many approaches such as association, classification, and abstraction to describe fuels in many different models although a universal fuel description system which can feed the existing multitude of fire behavior models is highly desirable. Future research should be focused at exploring the processes that govern fuel dynamics, such as deposition, decomposition, and accumulation, to understand how fuel characteristics change over time and space.

- Remote sensing tools. The possibility of frequent updating vegetation and fuel assessment by low-cost, easy to retrieve, multitemporal remotely sensed data (both passive and active, like LiDAR data) is distinctively critical to account for fuel dynamics. Furthermore, developing more accurate modeling linking diachronic remotely sensed data (e.g., temporal changes in LFMC, date of onset/offset of greenness, etc.) to risk of flammability is also required.

Acknowledgements This paper has been produced under the framework of the project MedWildFireLab ("Global Change Impacts on Wildland Fire Behaviour and Uses in Mediterranean Forest Ecosystems, towards a «wall less» Mediterranean Wildland Fire Laboratory") funded by ERANET FORESTERRA.

\section{References}

Akagi SK, Yokelson RJ, Wiedinmyer C, Alvarado MJ, Reid JS, Karl T, Wennberg PO (2011) Emission factors for open and domestic biomass burning for use in atmospheric models. Atm Chem and Phys 11:4039-4072

Andersen HE, McGaughey RJ, Reutebuch SE (2005) Estimating forest canopy fuel parameters using lidar data. Remote Sens Environ 94: 441-449

Anderson HE (1982) Aids to determining fuel models for estimating fire behavior. Rep. No. GTR INT-122. USDA, Forest Service, Ogden, UT

Anderson WR, Cruz MG, Fernandes PM, McCaw L, Vega JA, Bradstock R, Fogarty L, Gould J, McCarthy G, Marsden-Smedley JB, Matthews S, Mattingley G, Pearce G, Van Wilgen B (2015) A generic, empirical based model for predicting rate of fire spread in shrublands. Int J Wild Fire 24:443-460

Andreae MO, Merlet P (2001) Emission of trace gases and aerosols from biomass burning. Glob Biogeochem Cycles 15:955-966

Andrews PL, Bevins CD, Seli RC (2003) BehavePlus fire modeling system, version2.0: user's guide. Gen. Tech. Rep. RMRS-GTR106WWW. Department of Agriculture, Forest Service, Rocky Mountain Research Station, Ogden, UT 132p

Arroyo LA, Pascual C, Manzanera JA (2008) Fire models and methods to map fuel types: the role of remote sensing. Forest Ecol Manag 256: $1239-1252$
Bajocco S, Rosati L, Ricotta C (2010) Knowing fire incidence through fuel phenology: a remotely sensed approach. Ecol Model 221:59-66

Bajocco S, De Angelis A, Salvati L (2012) A satellite-based green index as a proxy for vegetation cover quality in a Mediterranean region. Ecol Indic 23:578-587

Bajocco S, Dragozi E, Gitas I, Smiraglia D, Salvati L, Ricotta C (2015) Mapping fuels through vegetation phenology: the role of coarseresolution satellite time-series. PLoS One 10:e0119811. doi:10.1371/journal.pone.0119811

Barbati A, Corona P, D'Amato E, Cartisano R (2015) Is landscape a driver of short-term wildfire recurrence? Landscape Res 40:99-108

Barboni T, Cannac M, Leoni E, Chiaramonti N (2011) Emission of biogenic volatile organic compounds involved in eruptive fire: implications for the safety of firefighters. Int J Wild Fire 20:152-161

Béland M, Baldocchi DD, Widlowski JL, Fournier RA, Verstraete MM (2014) On seeing the wood from the leaves and the role of voxel size in determining leaf area distribution of forests with terrestrial LiDAR. Agr. For. Met. 184:82-97

Brown ME, de Beurs K, Vrieling A (2010) The response of african land surface phenology to large scale climate oscillations. Rem Sens Env 114:2286-2296

Castro FX, Tudela A, Sebastia MT (2003) Modeling moisture content in shrubs to predict fire risk in Catalonia (Spain). Agr For Met 116:49 59

Chèret V, Denux JP (2007) Mapping wildfire danger at regional scale with an index model integrating coarse spatial resolution remote sensing data. J Geophys Res 112:G02006. doi:10.1029/2005 JG000125

Chetehouna K, Courty L, Mounaïm-Rousselle C, Halter F, Garo JP (2013) Combustion characteristics of p-cymene possibly involved in accelerating forest fires. Comb Sci Tech 185:1295-1305

Chetehouna K, Courty L, Garo JP, Viegas DX, Fernandez-Pello C (2014) Flammability limits of biogenic volatile organic compounds emitted by fire-heated vegetation (Rosmarinus officinalis) and their potential link with accelerating forest fires in canyons: a froude-scaling approach. J Fire Scie 32:316-327

Chirici G, Scotti R, Montaghi A, Barbati A, Cartisano R, Lopez G, Marchetti M, McRoberts RE, Olsson H, Corona P (2013) Stochastic gradient boosting classification trees for forest fuel types mapping through airborne laser scanning and IRS LISS-III imagery. Int J Applied Earth Obs Geoinf 25:87-97

Chuvieco E, Riano D, Aguado I, Cocero D (2002) Estimation of fuel moisture content from multi-temporal analysis of LANDSAT thematic mapper reflectance data: applications in fire danger assessment. Int J Rem Sens 23:2145-2162

Chuvieco E, Riaño D, van Wagtendonk J, Morsdorf F (2003) Fuel loads and fuel types. In: Chuvieco E (ed) Wildland fire danger estimation and mapping. The role of remote sensing data (pp. 1-32). World Scientific Publishing Co. Ltd, Singapore

Ciccioli P, Centritto M, Loreto F (2014) Biogenic volatile organic compound emissions from vegetation fires. Plant Cell Environ 37:1810 1825

Clarke PJ, Prior LD, French BJ, Vincent B, Knox KJE, Bowman DMJS (2014) Using a rainforest-flame forest mosaic to test the hypothesis that leaf and litter fuel flammability is under natural selection. Oecologia 176:1123-1133

Clerici N, Weissteiner CJ, Gerard F (2012) Exploring the use of MODIS NDVI-based phenology indicators for classifying forest general habitat categories. Remote Sens 4:1781-1803

Corona P, Cartisano R, Salvati L, Chirici G, Floris A, Di Martino P, Marchetti M, Scrinzi G, Clementel F, Travaglini D, Torresan C (2012) Airborne laser scanning to support forest resource management under alpine, temperate and Mediterranean environments in Italy. Eur Jo Rem Sens 45:27-37

Corona P, Ferrari P, Cartisano R, Barbati A (2014) Calibration assessment of forest flammability potential in Italy. iForest 7:300-305 
Côté JF, Fournier RA, Egli R (2011) An architectural model of trees to estimate forest structural attributes using terrestrial LiDAR. Environ Model Softw 26:761-777

Courty L, Chetehouna K, Garo JP, Fernandez-Pello C (2014) Experimental investigations on accelerating forest fires thermochemical hypothesis 4, 23-30. Book chapter in "Advances in forest fire research", Domingos Xavier Viegas Ed. doi: 10.14195/978-98926-0884-6 22

Curt T, Borgniet L, Bouillon C (2013) Wildfire frequency varies with the size and shape of fuel types in southeastern France: implications for environmental management. J Environ Manag 117:150-161

De Angelis A, Bajocco S, Ricotta C (2012) Phenological variability drives the distribution of wildfires in Sardinia. Landsc Ecol 27: $1535-1545$

de Beurs KM, Henebry GM (2005) Land surface phenology and temperature variation in the IGBP high-latitude transects. Glob Chang Biol 11:779-790

De Lillis M, Bianco PM, Loreto F (2009) The influence of leaf water content and isoprenoids on flammability of some Mediterranean woody species. Int J Wildland Fire 18:203-212

Della Rocca G, Hernando C, Madrigal J, Danti R, Moya J, Guijarro M, Pecchioli A, Moya B (2015) Possible land management uses of common cypress to reduce wildfire initiation risk: a laboratory study. J Environ Manag 159:68-77

Dimitrakopoulos AP (2001) A statistical classification of Mediterranean species based on their flammability components. Int J Wildland Fire 10:113-118

Dimitrakopoulos AP, Papaioannou KK (2001) Flammability assessment of Mediterranean forest fuels. Fire Techn 37:146-152

Dimitrakopoulos AP, Mitsopoulos ID, Gatoulas K (2010) Assessing ignition probability and moisture of extinction in a Mediterranean grass fuel. Int J Wildland Fire 19:29-34

Erdody TL, Moskal LM (2010) Fusion of LiDAR and imagery for estimating forest canopy fuels. Remote Sens Environ 114:725-737

Etlinger MG, Beall FC (2004) Development of a laboratory protocol for fire performance of landscape plants. Int J Wildland Fire 13:479 488

Fares S, Mereu S, Scarascia Mugnozza G, Vitale M, Manes F, Frattoni M, Ciccioli P, Gerosa G, Loreto F (2009) The ACCENT-VOCBAS field campaign on biosphere-atmosphere interactions in a Mediterranean ecosystem of Castelporziano (Rome): site characteristics, climatic and meteorological conditions, and eco-physiology of vegetation. Biogeoscie 6:1043-1058

Fares S, Scarascia Mugnozza G, Corona P, Palahi M (2015) Five steps for managing Europe's forests. Nature 519:407-409

Fensholt R, Sandholt I (2003) Derivation of a shortwave infrared water stress index from MODIS near- and shortwave infrared data in a semiarid environment. Remote Sens Environ 87:111-121

Fensholt R, Langanke T, Rasmussen K, Reenberg A, Prince SD, Tucker CJ, Scholes RJ, Le QG, Bondeau A, Eastman E, Epstein H, Gaughan AE, Hellden U, Mbow C, Olsson L, Paruelo J, Schweitzer C, Seaquist J, Wessels K (2012) Greenness in semi-arid areas across the globe 1981-2007 — an earth observing satellite based analysis of trends and drivers. Remote Sens Environ 121:144-158

Fernandes P, Cruz MG (2012) Plant flammability experiments offer limited insight into vegetation fire dynamics interactions. New Phytol. 194:606-609

Finney MA, Cohen JD, Forthofer JM, McAllister SS, Gollner MJ, Gorham DJ, Saito K, Akafuah NK, Adam BA, English JD (2015) Role of buoyant flame dynamics in wildfire spread. PNAS 112: 9833-9838

Fiorucci P, Gaetani F, Lanorte A, Lasaponara R (2007) Dynamic fire danger mapping from satellite imagery and meteorological forecast data. Earth Interact 11:1-17
Friedl MA, McIver DK, Hodges JCF, Zhang XY, Muchoney D, Strahler $\mathrm{AH}$ et al (2002) Global land cover mapping from MODIS: algorithms and early results. Remote Sens Environ 83:287-302

Ganteaume A, Jappiot M, Lampin C, Guijarro M, Hernando C (2013) Flammability of some ornamental species in wildland-urban interfaces in southeastern France: laboratory assessment at particle level. Environ Manag 52:467-480

García M, Riaño D, Chuvieco E, Salas J, Danson FM (2011) Multispectral and LiDAR data fusion for fuel type mapping using support vector machine and decision rules. Remote Sens Environ 115:1369-1379

Gill AM, Moore PHR (1996) Ignitibility of leaves of Australian plants. CSIRO Division of Plant Industry, Canberra

Gill AM, Zylstra P (2005) Flammability of Australian forests. Aust For 68:87-93

Greenberg J, Friedli H, Guenther AB, Hanson D, Harley P, Karl T (2006) Volatile organic emissions from the distillation and pyrolysis of vegetation. Atm. Chem. Phys. 6:81-91

Grootemaat S, Wright IJ, van Bodegom PM, Cornelissen JHC, Cornwell WK (2015) Burn or rot: leaf traits explain why flammability and decomposability are decoupled across species. Funct Ecol 29:14861497

Gudmundsson L, Rego FC, Rocha M, Seneviratne SI (2014) Predicting above normal wildfire activity in southern Europe as a function of meteorological drought. Environ Res Lett 9:084008

Guenther A, Karl T, Harley P, Wiedinmyer C, Palmer PI, Geron C (2006) Estimates of global terrestrial isoprene emissions using MEGAN (Model of Emissions of Gases and Aerosols from Nature). Atm Chem Phys 6:3181-3210

Hachmi M, Sesbou A, Benjelloun H, El Handouz N, Bouanane F (2011) A simple technique to estimate the flammability index of Moroccan forest fuels. J. Comb. Vol. 2011, Article ID 263531, 11 pp. doi: $10.1155 / 2011 / 263531$

Hargrove WW, Spruce JP, Gasser GE, Hoffman FM (2009) Toward a national early warning system for forest disturbances using remotely sensed canopy phenology. Photogramm Eng Remote Sens 75:1150 1156

Hosoi F, Omasa K (2006) Voxel based 3D modeling of individual trees for estimating leaf area density using high-resolution portable scanning LiDAR. IEEE Trans Geosc RemSens 44:3610-3618

Hosoi F, Omasa K (2007) Factors contributing to accuracy in the estimation of the woody canopy leaf area density profile using $3 \mathrm{D}$ portable LiDAR imaging. J Exp Botany 58:3463-3473

Hug C, Ullrich A, Grimm A (2004) LiteMapper-5600 - a waveformdigitizing LiDAR terrain and vegetation mapping system. In: Proceedings of the ISPRS workshop on laser scanners for forest and landscape assessment, Freiburg Germany, Vol. 36, pp. 24-29

Hunt RE, Rock RN (1989) Detection of changes in leaf water content using near-and middle-infrared reflectances. Remote Sens Environ 30:43-54

Ivits E, Cherlet M, Tóth G, Sommer S, Mehl W, Vogt J, Micale F (2012) Combining satellite derived phenology with climate data for climate change impact assessment. Glob Planet Chang 88-89:85-97

Jeong SJ, Ho CH, Gim HJ, Brown ME (2011) Phenology shifts at start vs. end of growing season in temperate vegetation over the northern hemisphere for the period 1982-2008. Glob Chang Biol 17:23852399

Jolly WM, Hadlow AM, Huguet K (2014) De-coupling seasonal changes in water content and dry matter to predict live conifer foliar moisture content. Int J Wildland Fire 23:480-489

Keane RE (2013) Describing wildland surface fuel loading for fire management: a review of approaches, methods and systems. Int $\mathrm{J}$ Wildland Fire 22:51-62

Kesselmeier J, Staudt M (1999) Biogenic volatile organic compounds (VOC): an overview on emission, physiology and ecology. J Atmos Chem 33:23-88 
Koetz B, Morsdorf F, van der Linden S, Curt T, Allgöwer B (2008) Multisource land cover classification for forest fire management based on imaging spectrometry and LiDAR data. For Ecol Manag 256:263271

Kolström M, Lindner M, Vilén T, Maroschek M, Seidl R, Lexer MJ, Netherer S, Kremer A, Delzon S, Barbati A, Marchetti M, Corona $P$ (2011) Reviewing the science and implementation of climate change adaptation measures in European forestry. Forests 2:961982

Lasaponara R (2005) Inter-comparison of AHVRR-based fire susceptibility indicators for the Mediterranean ecosystems of Southern Italy. Int J Rem Sens 26:853-870

Lindner M, Maroschek M, Netherer S, Kremer A, Barbati A, GarciaGonzalo J, Seidl R, Delzon S, Corona P, Kolstrom M, Lexer MJ, Marchetti M (2010) Climate change impacts, adaptive capacity, and vulnerability of European forest ecosystems. For Ecol Manag 259: 698-709

Lusini I, Pallozzi E, Corona P, Ciccioli P, Calfapietra C (2014) Novel application of a combustion chamber for experimental assessment of biomass burning emission. Atmos Environ 94:117-125

Ma X, Huete A, Yu Q, Restrepo Coupe N, Davies K, Broich M, Ratana P, Beringer J, Hutley LB, Cleverly J, Boulain N, Eamus D (2013) Spatial patterns and temporal dynamics in savanna vegetation phenology across the north Australian tropical transect. Remote Sens Environ 139:97-115

Madrigal J, Hernando C, Guijarro M, Díez C, Marino E (2009) Evaluation of forest fuel flammability and combustion properties with an adapted mass loss calorimeter device. J. Fire Sci. 27:323342

Madrigal J, Marino E, Guijarro M, Hernando C, Díez C (2012) Evaluation of the flammability of gorse (Ulex europaeus L.) managed by prescribed burning. Ann For Sci 69:387-397

Madrigal J, Hernando C, Guijarro M (2013) A new bench-scale methodology for evaluating the flammability of live forest fuels. J Fire Sci 31:131-142

Marino E, Hernando C, Madrigal J, Díez C, Guijarro M (2012) Fuel management effectiveness in a mixed heathland: a comparison of the effect of different treatments types on fire initiation risk. Int $\mathrm{J}$ Wildland Fire 21:969-979

Mavrakis A, Salvati L (2015) Analyzing trends in selected risk indices during the 2007 Greek forest fires. Int J Environ Res 9:831-840

Montaghi A, Corona P, Dalponte M, Gianelle D, Chirici G, Olsson H (2013) Airborne laser scanning of forest resources: an overview of research in Italy as a commentary case study. Int J Appl Earth Obs Geoinf 23:288-300

Moreira F, Viedma O, Arianoutsou M, Curt T, Koutsias N, Rigolot E, Barbati A, Corona P, Vaz P, Xanthopoulos G, Mouillot F, Bilgili E (2011) Landscape-wildfire interactions in southern Europe: implications for landscape management. J Environ Manag 92:2389-2402

Moriondo M, Good P, Durao R, Bindi M, Giannakopoulos C, Corte-Real J (2006) Potential impact of climate change on fire risk in the Mediterranean area. Clim Res 31:85-95

Morisette JT, Richardson AD, Knapp AK (2009) Tracking the rhythm of the seasons in the face of global change: phenological research in the 21st century. Front Ecol Environ 7:253-260

Mutlu M, Popescu S, Stripling C, Spencer T (2008) Mapping surface fuel models using LiDAR and multispectral data fusion for fire behavior. Remote Sens Environ 112:274-285

National Science and Analysis Team (NSAT) (2012) Scientific basis for modelling wildland fire management: the phase II report of the national science and analysis team. 71 p. Available at: http://www. forestsandrangelands.gov/strategy/documents/reports/phase2/NSAT Phase 2 Summary Report.pdf

Nemani R, Hashimoto H, Votava P (2009) Monitoring and forecasting ecosystem dynamics using the Terrestrial Observation and Prediction System (TOPS). Remote Sens Environ 113:1497-1509
Olsen JL, Stisen S, Proud SR, Fensholt R (2015) Evaluating EO-based canopy water stress from seasonally detrended NDVI and SIWSI with modeled evapotranspiration in the Senegal river basin. Remote Sens Environ 159:57-69

Owens MK, Lin CD, Taylor CA, Whisenant SG (1998) Seasonal patterns of plant flammability and monoterpenoid content in Juniperus ashei. J Chem Ecol 24:2115-2129

Page WG, Jenkins MJ, Runyon JB (2012) Mountain pine beetle attack alters the chemistry and flammability of lodgepole pine foliage. Can J For Res 42:1631-1647

Pan Y, Birdsey RA, Fang J, Houghton R, Kauppi PE, Kurz WA et al (2011) A large and persistent carbon sink in the world's forests. Science 333:988-993

Pausas JG, Alessio GA, Moreira B, Corcobado G (2012) Fires enhance flammability in Ulex parviflorus. New Phytol 193:18-23

Pellizzaro G, Cesaraccio C, Duce P, Ventura A, Zara P (2007) Relationships between seasonal patterns of live fuel moisture and meteorological drought indices for Mediterranean shrubland species. Int J Wild Fire 16:232-241

Peñuelas J, Munne-Bosch S, Llusia J, Filella I (2004) Leaf reflectance and photo- and antioxidant protection in field-grown summer-stressed Phillyrea angustifolia. Optical signals of oxidative stress? New Phytol. 162:115-124

Pettorelli N, Vik JO, Mysterud A, Gaillard JM, Tucker CJ, Stenseth NC (2005) Using the satellite-derived NDVI to assess ecological responses to environmental change. Trends Ecol Evol 20:503-510

Pimont F, Dupuy JL, Rigolot E, Prat V, Piboule A (2015) Estimating leaf bulk density distribution in a tree canopy using terrestrial LiDAR and a straightforward calibration procedure. Remote Sens 7:79958018

Reimann S, Lewis CA (2007) Anthropogenic VOCs. In volatile organic compounds in the atmosphere (ed R. Koppmann), pp. 33-70. Blackwell Publishing, Oxford

Riaño D, Meier E, Allgower B, Chuvieco E, Ustin S (2003) Modeling airborne laser scanning data for the spatial generation of critical forest parameters in fire behavior modeling. Remote Sens Environ $86: 177-186$

Riaño D, Chuvieco E, Ustin S, Salas F, Rodriguez-Perez J, Ribeiro L, Viegas D, Moreno J, Fernandez H (2007) Estimation of shrub height for fuel type mapping combining airborne LiDAR and simultaneous colour infrared images. Int J Wildland Fire 16:341-348

Rossa CG, Veloso R, Fernandes PM (2016) A laboratory-based quantification of the effect of live fuel moisture content on fire spread rate. Int J Wildland Fire 25:569-573

Rowell RM, Pettersen R, Tshabalala MA (2012) Cell wall chemistry. In handbook of wood chemistry and wood composites (ed. R.M. Rowell), pp. 35-74. CRC Press, London

Salvati L, Ferrara A (2015) Do land-use changes shape sensitivity to forest fires in peri-urban areas? Urban for. Urban Greening 13: $571-575$

Scarff FR, Gray BF, Westoby M (2012) Exploring phosphate effects on leaf flammability using a physical chemistry model. Int $\mathrm{J}$ Wildland Fire 21:1042-1051

Schwilk DW (2015) Dimensions of plant flammability. New Phytol 206: 486-488

Seielstad C, Queen L (2003) Using airborne laser altimetry to determine fuel models for estimating fire behavior. J For 101:10-15

Seielstad C, Stonesifer C, Rowell E, Queen L (2011) Deriving fuel mass by size class in Douglas-fir (Pseudotsuga menziesii) using terrestrial laser scanning. Remote Sens 3:1691-1709

Simpson IJ, Akagi SK, Barletta B, Blake NJ, Choi Y, Diskin GS, Blake DR (2011) Boreal forest fire emissions in fresh Canadian smoke plumes: $\mathrm{C} 1-\mathrm{C} 10$ volatile organic compounds (VOCs), $\mathrm{CO} 2, \mathrm{CO}$, $\mathrm{NO} 2, \mathrm{NO}, \mathrm{HCN}$ and $\mathrm{CH} 3 \mathrm{CN}$. Atmos Chem Phys 11:6445-6463 
Skowronski NS, Clark KL, Duveneck M, Hom J (2011) Threedimensional canopy fuel predicted using upward and downward sensing LiDAR systems. Remote Sens Environ 115:703-714

Sow M, Mbow C, Hély C, Fensholt R, Sambou B (2013) Estimation of herbaceous fuel moisture content using vegetation indices and land surface temperature from MODIS data. Remote Sens 5:2617-2638

Thompson MP, Calkin DE (2011) Uncertainty and risk in wildland fire management: a review. J Environ Manag 92:1895-1909

Thonicke K, Cramer W (2006) Long-term trends in vegetation dynamics and forest fire in Brandenburg (Germany) under a changing climate. Nat Hazards 38:283-300

Tilman D, Reich P, Phillips H, Menton M, Patel A, Vos E, Peterson DL, Knops J (2000) Fire suppression and ecosystem carbon storage. Ecology 81:2680-2685

Urbanski SP, Hao WM, Baker S (2009) Chemical composition of wildland fire emissions. In developments in environmental science (eds A. Bytnerowicz, M. Arbaugh, A. Riebauand C. Andersen), pp. 79 107. Elsevier, The Netherlands

Van der Werf GR, Randerson JT, Giglio L, Collatz GJ, Mu M, Kasibhatla PS, Morton DC, DeFries RS, Jin Y, van Leeuwen TT (2010) Global fire emissions and the contribution of deforestation, savanna, forest, agricultural, and peat fires (1997-2009). Atmos Chem Phys 10: $11707-11735$

Varner JM, Kane JM, Kreye JK, Engber E (2015) The flammability of forest and woodland litter: a synthesis. Curr Forestry Rep 1:91-99
Verbesselt A, Fleck S, Coppin P (2003) Estimation of fuel moisture content towards fire risk assessment: a review. In: Viegas (ed) Forest fire research and wildland fire safety. Millpress, Rotterdam

Viegas DX, Piñol J, Viegas MT, Ogaya R (2001) Estimating live fine fuels moisture content using meteorologically-based indices. Int $\mathrm{J}$ Wildland Fire 10:223-240

Weise DR, Zhou X, Sun L, Mahalingam S (2005) Fire spread in chaparral- "go or no go?". Int J of Wild Fire 14:99-106

White MA, Hoffman FM, Hargrove WW, Nemani RR (2005) A global framework for monitoring phenological responses to climate change. Geophys Res Lett 32:L04705. doi:10.1029/2004GL021961

Xanthopoulos G, Caballero D, Galante M, Galante D, Rigolot E, Marzano R (2006) Forest fuels management in Europe. USDA forest service proceedings RMRS-P-41

Xanthopoulos G, Calfapietra C, Fernandes P (2012) fire hazard and flammability of European forest types. In: Moreira F. Arianoutsou M. corona P. De las Heras J. (Eds.) Post-fire management and restoration of southern European forests. Springer-Managing Forest Ecosystems 24: 93-120

Yebra M, Dennison PE, Chuvieco E, Riaño D, Zylstra P, Hunt ER, Jurdao S (2013) A global review of remote sensing of live fuel moisture content for fire danger assessment: moving towards operational products. Remote Sens Environ 136:455-468

Zhou X, Mahalingam S, Weise D (2005) Modeling of marginal burning state of fire spread in live chaparral shrub fuel bed. Comb Flame $143: 183-198$ 